\title{
Carers' experiences with overnight respite care. A qualitative study
}

\begin{abstract}
Aud-Mari Sohini Fjelltun, Post doc, PhD, RN, MSc - Nils Henriksen, PhD, MSc, Associate Professor - Astrid Norberg, PhD, RN Professor - Fredricka Gilje, PhD, RN, CS Associate Professor - Hans Ketil Normann, PhD, RN, RNT, MSc Associate Professor
\end{abstract}

\section{ABSTRACT}

Aim. The aim of this study was to explore experiences with overnight respite care (ORC) of Norwegian carers who provided care to frail elderly awaiting nursing home placement.

Background. In many Western countries respite care has become part of health care service provision, and various types of respite care are available. The intent with respite care can be twofold; caring for the care receiver and supporting the carer.

Methods. This is a descriptive qualitative study. Interviews were conducted with 15 carers, transcribed and analysed by qualitative content analysis.

Findings. The carers described various experiences with ORC. If ORC supported the whole family, it was welcomed by carers and experienced as supportive. If ORC did not support the whole family, many carers rejected ORC, and it was experienced as non-supportive. Two categories were constructed: 'experiencing ORC as supportive for the family as a whole' and 'not experiencing ORC as supportive for the family as a whole'.

Conclusion. To support more carers, nurses have to listen to carers' experiences about ORC. Nurses need to take responsibility for the family as a whole and provide more flexible ORC services based on both carers' and elderly's needs.

KEY WORDS: Nurse, family caregiver, carer, elderly, respite care

\section{Introduction}

In Norway, the number of frail elderly is increasing (1). Due to a lack of nursing home $(\mathrm{NH})$ beds (2), many elderly have long waiting periods after NH has been assessed as needed. Carers' workload in home care of elderly has been well documented (3). Some Norwegian carers of elderly awaiting $\mathrm{NH}$ placement rated their levels of workload maximal according to their capacities. Some of them were old, frail and about to become patients themselves. They were in great need of individually adjusted support to be able to continue their caregiving (4). In response to carers' need, respite care has been developed (5) to support carers by offering them temporary relief and assisting them in maintaining their relative at home (6). The purpose of overnight respite care (ORC) is twofold: to give the elderly more extensive care and/or training than possible at home, and to give carers temporary relief. Since the elderly's and carers conditions are closely intertwined and affect all family members, ORC can support the whole family. This study focuses on carers' experiences with ORC in a NH or a rehabilitation unit, lasting up to three weeks. Norwegian municipalities have a juridical duty to offer respite care to families providing particularly burdensome care (7). Despite a recommendation by the Norwegian Board of Health (8) to use $15 \%$ of $\mathrm{NH}$ beds for ORC to provide adequate respite care, one-third of 37 Norwegian municipalities lacked ORC beds in 2005 (9).

Research about outcomes of respite care has shown: small positive benefits of ORC as part of a respite package; ORC reduced carers' burden and improved their mental or physical health (10); no statistically significant effects of any respite care (11); respite services not sufficiently meeting carers' needs (12); small but significant effects on carers of persons with dementia disease, by reducing their burden and depressive symptoms (13); no evidence of delay of entry to residential care (10). ORC could be a transitional service before or an accelerating factor to permanent $\mathrm{NH}$ placement (14); and enabling some carers to continue caregiving being overwhelmingly satisfied with ORC (15-16).

A review article showed $22-50 \%$ of carers rejected respite care, even when financial barriers were removed (17). The most often reason for refusal of American carers was the elderly's resistance (18). Other carers felt guilty about accepting respite care because the elderly might think they were unable to cope with the situation (19). Some Finnish carers welcomed respite care as a relief, but did not benefit from it because of guilt, troubled conscience and loneliness (20). Some Canadian carers experienced guilt following ORC, especially if the elderly's condition declined (21). Mason et al. (10) found no adverse effects on the elderly. Many American carers worried about the quality of respite care (18). It was important to some Australian carers that the elderly were well cared for, happy and had opportunities to socialise with others at ORC (14).

\section{The study}

In this study, we explored how carers of elderly awaiting $\mathrm{NH}$ placement experienced ORC. Because these elderly were particularly frail and actually needed $\mathrm{NH}$ care, ORC might be important to their carers during the waiting period. These carers differed from other carers because they had requested $\mathrm{NH}$ placement, which meant they actually wanted to end their caregiving. Still, because of a lack of NH beds, they had to continue giving care, perhaps beyond their boundaries. Illuminating carers' experiences with ORC may contribute to a broader understanding of how community nurses can support exhausted carers.

\section{Aim}

The aim of this study was to explore the experiences with ORC of Norwegian carers who provided care to frail elderly awaiting NH placement.

\section{Design/Methodology}

This is a descriptive study. Semi-structured interviews were performed and analysed by qualitative content analysis (22).

\section{Sample/Participants}

This study was conducted in a municipality in northern Norway. A convenient sample of 15 carers of the elderly awaiting NH placement (seven men, eight women; 71-99 years; Median $=85$; 10 with advanced dementia disease; eight living alone) were invited to participate by the head nurse in their home services area. Inclusion criteria were providing care to the elderly on a municipal $\mathrm{NH}$ waiting list $(\mathrm{n}=63)$ and Norwegian speaking. Breadth and diversity in data were desired. Thus, participants were selected with different kinship to the elderly and varying degrees of workload. There were six wives aged 70-83 years, three sons aged 60-62 years, and six daughters aged 44-72 


\section{Table I. Overview of the questions in the semi-structured interviews}

Mainquestion:

How is it like to be carer for an old person awaiting NH placement?

1. Introductory: Please, narrate about your relative, - from when you started giving care till now.

2. Daily routines: Please, narrate about a normal day. Emphasize the help you give to your relative.

3. Home health services: Please, narrate about your experiences with home health services.

4. The future: Please, narrate about your thoughts for the future, yourself and your relative.

5. The carer: Has giving care altered you as a person, or in any ways changed your life? What have you learned?

6. Closing question: What do you consider as most important of what we have talked about?

Table II. Meaning units, condensations, sub-categories and category in the qualitative content analysis

Meaning units

'We are not complaining. After we had ORC regularly, I was able to continue the caregiving'.

'I went to the cottage because there I can relax'.

Condensations
Regular ORC helped
the carer to continue the caregiving.

The carer was able to relax.

'In the $\mathrm{NH}$, the conditions were adjusted to his needs, so he was improving'.

'She is seldom content, but this The elderly was

time she was really thriving and thriving at ORC. appreciated the good service'.
The elderly was improving at ORC.
Sub-categories

Being able to

continue caregiving

because of ORC.

Engaging in refreshing Experiencing activities and relaxation.

Being satisfied with

ORC's quality

and/or regularity.

Experiencing the

elderly's satisfaction

and benefits from ORC.
ORC as supportive for the family as a whole.

content analysis (22). The co-authors audited the textual analysis by reading and re-reading sections of the interviews and identifying differences, similarities and patterns in the text. All interviews were divided into meaning units that were coded, condensed and abstracted. To address trustworthiness, co-authors who were experienced in elderly research and the research method, checked and discussed analysis and interpretations to reach consensus. Nine sub-categories were constructed and grouped into two categories: 'experiencing ORC as supportive for the family as a whole' and 'not experiencing ORC as supportive for the family as a whole'. Table II contains an example of the analysis process. An overview of sub-categories and categories is given in Table III.

\section{Ethical considerations}

The Head of the Social Welfare Unit at the municipality and the National Committees for Research Ethics in Norway (57/2004) approved the study.

Participants received an explanatory letter from the head nurse in their home services area inviting their participation. They were promised confidentiality and anonymous presentations of findings, guaranteed that participation was voluntary and informed they had the right to withdraw at any time without stating a reason. Before data collection began, written informed consent was obtained from each participant.

The interviews contained intimate questions about frail and vulnerable elderly awaiting $\mathrm{NH}$ placement. For elderly who could understand the

years. The caregiving period varied from one to more than 10 years. Ten carers provided care several times a day; six provided care more than eight hours daily. Eight carers were employed and worked outside the family.

\section{Data collection}

September-November 2005, carers were asked to narrate their experiences with elderly care, daily routines and health services. Data from question 3 'Please, narrate about your experiences with home health services', which included ORC, form the basis of this paper (Table I). Most interviews were conducted in the carers' home. All interviews $(n=15)$ lasted 50-60 minutes each, were audio-recorded, listened and re-listened to and transcribed verbatim, including emotional reactions as silence, sighs and laughter. The sample was considered adequate as new data informed the existing findings, but did not add anything new to them, indicating theoretical saturation (23).

Data analysis

The interviews (about 110000 words) were analyzed by qualitative information, carers asked for their informed consent before participating. If the elderly showed resistance towards the study, carers did not participate. If the elderly had advanced dementia disease and could not understand the information, carers conside-

red acting in the elderly's best interest.
Not experiencing ORC as a whole. supportive for the family as

\section{Findings}

There was great variation in carers' experiences with ORC. The following sections present the categories with sub-categories and quotations.

\section{'Experiencing ORC as supportive for the family as a whole'}

Some carers experienced ORC as supportive for the family as a whole. To accept and have advantages from ORC, it was crucial that ORC was advantageous for both the carers and the elderly in the long run.

\section{'Being able to continue caregiving because of ORC'}

One wife described how ORC provided the relief necessary for her coping. She was very exhausted and in poor health. Her husband had been offered permanent $\mathrm{NH}$ placement, but the wife did not want to lose his company and rejected the offer. Now, he got regular ORC making the wife able to continue caregiving a little longer. She narra- 
ted 'He does not want to go to the NH.... I have told him if I shall survive the caregiving, and we shall continue living together, he just has to.'

\section{'Engaging in refreshing activities and relaxation'}

Some carers were able to engage in refreshing activities while the elderly received ORC. Most carers regularly visited the elderly during ORC and it was difficult to travel a great distance. One wife narrated how she initially was reluctant to travel, but when she did, it was a great experience: 'I did not want to go, but it was a great journey. I experienced a lot of things.' Another wife went to the couple's cottage bringing her mobile phone, making herself available for contact.

\section{'Being satisfied with ORC's quality and/or regularity'}

One daughter was very satisfied with the quality of ORC. Her mother with advanced dementia disease was living alone, and the daughter often worried about her quality of life. However, with ORC, she knew her mother's basic needs were met. She said: 'They gave her attention, followed her to the toilet and regularly gave her food and medicines. She ate a lot. I think she really flourished.' When community services provided flexible respite arrangements, carers expressed satisfaction. Some elderly alternated between two weeks in $\mathrm{NH}$ and two weeks at home. In this way, carers received enough ORC to manage a burdensome situation.

\section{'Experiencing the elderly's satisfaction and benefits from ORC'}

Some carers narrated that it was easier to enjoy ORC when the elderly felt satisfied. Some elderly could flourish during ORC. One daughter said: 'The greatest effect of her ORC is that she can be together with other people for two or three weeks. It brings her out of her depression.' Another daughter narrated that her mother with advanced dementia disease was very pleased thinking the $\mathrm{NH}$ was a hotel.

'Not experiencing ORC as supportive for the family as a whole' Some carers did not experience ORC as supportive for the family as a whole. When the carer or the elderly had disadvantages from the ORC, carers were likely to reject further offers.

'Being dissatisfied with quality, security and/or unpredictability' Some carers expressed dissatisfaction with the quality of ORC. One wife described: 'The staff changes all the time. The few personnel are too busy. He can be sitting wet in urine the whole day.' Some elderly were not thriving at ORC because many residents had advanced dementia disease. One daughter narrated how her mother complained: 'She said: 'I will not stay at this place because everybody here is old and senile.' She cannot see that she is in the same category.' Cognitively well functioning elderly had similar experiences, and their carers found this was particularly difficult. One wife was dissatisfied with the security at the $\mathrm{NH}$. The doors were unlocked so that various kinds of people entered. Some carers said the organization of ORC lacked predictability and flexibility. They could not be informed in advance about ORC availability, which made planning meaningful activities difficult.

\section{'Being unable to engage in refreshing activities'}

Some carers narrated difficulties engaging in refreshing activities while the elderly received ORC. One wife said 'I had planned to do so many things when I finally got some time off, but I just sat there....' Some carers missed the elderly's company during ORC and visited them daily. Troubled conscience was a common feeling among carers.

\section{'Experiencing the elderly declining physically or mentally'}

Most carers reported decline in the elderly's activity of daily living (ADL) functions during ORC, especially when ORC was in a $\mathrm{NH}$. After ORC they had to work diligently to restore the elderly's earlier level of function. One daughter described 'He comes home a little reduced, and we have to give him some extra training. We have to speak directly into his ear: 'You have to stand, and you have to walk'. Perhaps they automatically nurse him in bed.' One wife did not like the use of a lift when her husband regularly received ORC every two weeks because it decreased his ability to stand up. Even in specialized rehabilitation units, some carers experienced a lack of time for training in mobility during ORC. Returning home again could be difficult, as one daughter narrated, whose mother had advanced dementia disease with high anxiety: 'She was at a respite stay for four weeks, and she felt safe and flourished with all the people surrounding her. The worst thing I have ever done was to take her back home... I cannot stand her being a shuttlecock.' After ORC, her mother became more confused and anxious, and she would telephone her daughter several times during the night.

\section{'Rejecting offers of ORC'}

One daughter, living with her mother, rejected ORC because she experienced it as too stressful. She narrated 'I find ORC too stressful, to get from home to $\mathrm{NH}$ and back again, and clothes constantly disappear.' Some carers stretched themselves to spare the elderly from unpleasant episodes and to conserve his/her dignity. One wife narrated that she was doing intimate washing as long as she could to spare her husband from being degraded by the nurses' care. Some carers hesitated to use ORC when the elderly rejected it. One wife described how she, although very exhausted herself, would not force her husband: 'I have promised to care for him as long as I can manage. I would feel like a traitor transferring him by force.' One son described how it seemed like his mother maintained a crystal clear opinion in spite of her advanced dementia disease. Throughout her adult life, she stated clearly she would never move to a NH. He narrated what happened when he told her about an ORC offer: 'It is the most obvious «no» I have heard in years. She shouted it over and over with increasing volume, and a look in her face expressing 'over my dead body', totally terrified.' Although he experienced the situation as hopeless, he rejected the offer because he could not move his mother against her will.

\section{'Wanting more ORC services'}

One son, living next to his mother, felt exhausted. His mother wanted ORC in a rehabilitation unit to train for mobility with the intention to improve her physical function, but they just had to wait. Some carers said that the elderly with tendencies to fall were prioritized too late for ORC. They had to fall several times before nurses understood the seriousness. Perhaps some falls could have been prevented with earlier ORC. One daughter narrated: 'One month he was at the emergency ward three times. At last the doctors said he was too frail to stay at home alone, and he finally got the ORC we had asked for.' Some carers thought they had a restricted quota of ORC, so although they needed regularly $\mathrm{ORC}$, they tried to economize with the number of weeks available and postponed their requirement. One daughter had not got any ORC. She had repeatedly requested ORC without any response. She did not know what more she could do and was about to give up.

\section{Discussion}

This study found great variation in Norwegian carers' experiences with ORC while caring for frail elderly awaiting NH placement. The same carers could have both positive and negative experiences.

\section{Supporting the family as a whole}

It was crucial to the carers that ORC was flexible and adjusted, meeting both the carers' and the elderly's needs. Then, ORC could be experienced as supportive for the family as a whole. To get the intermittent and necessary relief to be able to continue their caregiving, carers had to be assured of the elderly's safety and well-being. If ORC was not adjusted to meet the elderly's needs, some carers felt ORC even worsened their situation. A clear relationship was found between Canadian carers' ability to experience relief and the carers' perception that their relative was comfortable and safe $(24)$. Other studies $(10,13)$ have shown similar carer experiences .

The last 25 years, there has been an increasing interest in family focused nursing (25). The WHO has pointed out the nurses' responsibility for the health of the whole family when one family member gets a dis- 
ease (26). It is known, that other family members can be strongly affected by caregiving and the frailty of elderly awaiting $\mathrm{NH}$ placement (21).

\section{Functional decline of the elderly during ORC}

Some carers narrated that the elderly's ADL functions declined during ORC. This is contradictory to a literature review which found no evidence of deterioration of the elderly during respite care (10). Nevertheless, some other studies have shown functional decline of elderly during ORC, for example in Canada and New Zealand, deterioration of the elderly during respite care was an important reason why many carers did not take advantage of the respite time $(21,27)$. One reason for our findings can be that the elderly were more frail than the care receivers in other studies as they were assessed to need $\mathrm{NH}$ care. In addition, by requesting $\mathrm{NH}$ placement, their carers had clearly signalled they wanted to end caregiving. During ORC, there may have been a lack of physiotherapy, occupational therapy or activities to provide the elderly with sufficient training and activities which may have resulted in the ADL decline, too. This is what one of the carers described. Before ORC, the elderly's levels of functioning could be marginal for carers to handle and a slight decline in the elderly's ADL functions could make caregiving unbearable for these carers. Still, some carers accepted ORC because they could not continue caregiving without respite care. An example of this was the wife who complained about the NH staff's use of a mechanical lift for her husband during ORC, resulting in his reduced ability to stand. The lift was a reasonable device to physically protect the staff and perhaps the wife should have a lift at home to protect her as well. Research has shown that if outcomes for the elderly were negative, many carers did neither benefit from respite care nor accept it (28).

\section{Refusal of ORC}

Some elderly refused to move to a NH, even for ORC, and few carers would forcefully move their loved ones. Research has shown that the elderly's refusal was a common reason for carers not to use respite care (18). According to Norwegian laws, it is illegal to move the elderly to ORC by coercion. During the course of advanced dementia disease, many elderly become incompetent to give informed consent, and their next of kin may consent on their behalf (29). Still, it was difficult for some carers to accept ORC on behalf of the elderly when they previously refused ORC and could not be persuaded to accept it. Instead, these carers tried to manage without ORC and became more and more exhausted. In the Netherlands, some respite care programs have been designed to help the carers and the elderly to overcome their initial resistance (30). Moving to a $\mathrm{NH}$ has been reported as stressful, even for the elderly who accepted respite care (31). Relocation of the elderly has resulted in conditions, such as confusion and changes in mortality rates and morbidity (32). More flexible home health services, like home-based ORC, might be a way to offer the carers temporary relief without moving the elderly.

\section{Lacking sufficient ORC}

Although Norwegian families with particularly burdensome care have a right to respite care (7) some carers had difficulty obtaining sufficient ORC. The lack of respite care is not only a Norwegian phenomenon; it was also a problem in Canada (33), Finland (34) and Sweden (35). Harrison and Neufeld (36) reported some carers had several barriers requesting support for themselves. It was somewhat easier to accept support if it was offered to them. This finding is important for community nurses to consider and avoid offering ORC only to carers who repeatedly request it.

\section{Study limitations}

Study strengths are that the carers were encouraged to freely narrate their experiences of giving care to the elderly, which provided rich textual data, and that the researchers were experienced in elderly research. One limitation is that in the interview guide, ORC was not a central subject. Therefore, few questions was made clearly about ORC. The subject appeared important during the analysis. Still, the most important limitation is that the study included only carers' experiences with ORC. The elderly who received ORC were not interviewed. Recommendations for further research are to appraise the elderly's levels of functioning before and after ORC, implement an observational study to deepen the understanding of ORC and interview the elderly receiving ORC to illuminate their experiences. While the context for this study was a community in Norway, these findings may be transferable to similar settings. Information about the research process and the Norwegian society allows readers to appraise the study's transferability.

\section{Conclusions}

This study explored the experiences of Norwegian carers with ORC while caring for frail elderly awaiting $\mathrm{NH}$ placement. The findings showed that to support the carers, ORC had to be adjusted both to the carers' and the elderly's needs. Since there was a great complexity in the situations, ORC could be organized with more flexible services. Perhaps some elderly who refused ORC would have benefited if home-based ORC could have been provided.

In spite of insufficient resources in home health care, providing appropriate support for the elderly and their carers means that nurses have to consider the individual concerns in each situation. Nurses need to acknowledge an ethical responsibility for the family as a whole. They have to co-operate with the carers and listen to their experiences about ORC. Instead of providing a standard solution, the individual carers' and the individual elderly's needs should be considered. In addition, nurses need to contribute to policy revisions by advocating for funding, pointing out invidious consequences for both the elderly and their carers.

\section{Funding}

Fundings for this study was received from Centre for Research in the Elderly in Tromsoe (project number SAT259-05)

\section{Accepted for publication 4.08.2009}

Aud-Mari Sohini Fjelltun ${ }^{1}$, Nils Henriksen ${ }^{1}$, Astrid Norberg ${ }^{1,2}$, Fredricka Gilje ${ }^{3}$ Hans Ketil Normann ${ }^{1}$

1 Institute for Health and Care Sciences,University of Tromso, NO - 9037 Troms $\varnothing$

${ }^{2}$ Ersta Sköndal University College, Stockholm, Sweden; Department of Nursing, Umeå University, SE-90187 Umeå, Sweden.

${ }^{3}$ School of Nursing, University of Alaska Anchorage, Anchorage, AK, USA.

Correspondence: Aud-Mari Sohini Fjelltun, Institute for Health and Care Sciences, University of Tromso, NO - 9037 Troms $\varnothing$

E-mail:Aud.Mari.Fjelltun@uit.no

\section{References}

1. Statistics Norway. Befolkningsframskrivinger. Nasjonale og regionale tall, 2005-2060. (Population projections. National and regional numbers, 2005-2060). Statistisk Sentralbyrå 2006; Oslo.

2. Ministry of Health and Care Services. Mestring, muligheter og mening. Framtidas omsorgsutfordringer. Stortingsmelding nr. 25. Helse- og Omsorgsdepartementet. 2006; Oslo. (Coping, possibilities and meaning. Care challenges in the future. Norwegian).

3. Sherwood, P, Given, C, Given, B, von Eye, A. Caregiver burden and depressive symptoms: Analysis of common outcomes in caregivers of elderly patients. Journal of Aging and Health 2005;17:125-147.

4. Fjelltun AMS, Henriksen N, Norberg A, Gilje F, Normann HK. Nurses' and carers' appraisals of workload in care of frail elderly awaiting nursing home placement. Scandinavian Journal of Caring Sciences 2009; 23: 57-66.

5. Statistics Norway. Recipients of respite care, by region, age, time and contents. Table 03318: Recipients of respite care (M). Statistisk sentralbyrå (Statistics Norway). 2007; Oslo. 
6. Gilmour JA. Dis/integrated care: family caregivers and in-hospital respite care. Journal of Advanced Nursing 2002;39:546-553.

7. Ministry of Health and Care Services. Lov om sosiale tjenester. Helse- og Omsorgsdepartementet. 1991; Oslo. (Act relating to social services. Norwegian).

8. Norwegian Board of Health. Pleie og omsorgstjenesten i kommunene: Tjenestemottakere, hjelpebehov og tilbud. Statens Helsetilsyn. Rapport 10/2003. 2003; Oslo. Nursing and care in municipalities: Receivers of services, needs of help and offers (Norwegian).

9.Otterstad HK, Tønseth H. Hvordan unngå sykehjemskø? Aldring og livsløp 2007;4:20-24. (How to avoid waiting lists for NH placement. Norwegian).

10. Mason A, Weatherly H, Spilsbury K, Golder S, Arksey H, Adamson J, Drummond M. The effectiveness and cost-effectiveness of respite for caregivers of frail older people. Journal of the American Geriatrics Society 2007;55:290-299.

11. Lee H, Cameron M. Respite care for people with dementia and their carers Cochrane Database of Systematic Reviews (2), CD004396; 2004.

12. Stoltz P, Udén G, Willman A. (Support for family carers who care for an elderly person at home - a systematic literature review. Scandinavian Journal of Caring Sciences 2004;18:111-119.

13. Pinquart M, Sorensen S. Helping caregivers of persons with dementia: which interventions work and how large are their effects? International Psychogeriatrics 2006;18:577-595.

14. Zarit SH, Gaugler JE, Jarrott SE. Useful services for families: research findings and directions. International Journal of Geriatric Psychiatry 1999; 14:165-177.

15. Neville CC, Byrne GJA. Staff and home caregiver expectations of residential respite care for older people. Collegian 2007;14:27-31.

16. Hancock PJ, Jarvis JA. Evaluation of the Australian Commonwealth Respite Care Program: A case study from Western Australia and the Australian Red Cross. Evaluation and Program Planning 2005;28:301-311.

17. Gottlieb BH, Johnson J. Respite programs for caregivers of persons with dementia: a review with practice implications. Aging and Mental Health 2000;4:119-129.

18. Winslow BW. Family caregivers' experiences with community services: a qualitative analysis. Public Health Nursing 2003;20:341-348.

19. Vetter NJ. Respite care. Reviews in Clinical Gerontology 2002;12: 181-186.

20. Salin S, Åstedt-Kurki P. Women's views of caring for family members: use of respite care. Journal of Gerontological Nursing 2007;33:37-45.

21. Strang VR. Caregiver respite: coming back after being away. Perspectives 2000;24:10-20.

22. Graneheim UH, Lundman B. Qualitative content analysis in nursing research: concepts, procedures and measures to achieve trustworthiness. Nurse Education Today 2004;24:105-112.

23. Milne J, Oberle K. Enhancing rigor in qualitative description. A case study. Journal of Wound, Ostomy and Continence Nursing 2005;32: 413-420.

24. Evaluation of a weekend respite program for persons with Alzheimer Disease. Canadian Journal of Nursing Research 2001;33:81-95.

25. Benzein E, Hagberg M, Saveman B. 'Being appropriately unusual': a challenge for nurses in health-promoting conversations with families. Nursing Inquiry 2008;15: 106-115.

26. World Health Organisation (WHO) Europe. HEALT 21: The health for all policy framework for the WHO European region. WHO Regional Office for Europe. European Health for All Series No. 5. 1998; Copenhagen.

27. Gilmour JA. Dis/integrated care: family caregivers and in-hospital respite care. Journal of Advanced Nursing 2002;39:546-553.

28. Witt E, Chenoweth LL, Jeon Y. Respite services for older persons and their family carers in southern Sydney. Collegian 2004;11:31-35.

29. Ministry of Health and Care Services. Lov om pasientrettigheter. Helse- og Omsorgsdepartementet. 1999; Oslo. (Act relating to patients' rights. Norwegian).

30. van Exel J, de Graaf G, Brouwer W. Care for a break? An investigation of informal caregivers' attitudes toward respite care using Q-methodology. Health Policy; 2007:332-342.

31. Lee DTF, Woo J, Mackenzie AE. A review of older people's experiences with residential care placement. Journal of Advanced Nursing 2002;37: 19-27.
32. Castle NG. Relocation of the elderly. Medical Care Research and Review 2001;58:291-333

33. Armstrong-Esther C, Hagen B, Sandilands M, Williams R, Smith C. A longitudinal study of home care clients and their informal carers. British Journal of Community Nursing 2005;10:284-291.

34. Raivio M, Eloniemi-Sulkava U, Laakonen M, Saarenheimo M, Pietilä M, Tilvis R, Pitkälä K. How do officially organized services meet the needs of elderly caregivers and their spouses with Alzheimer's Disease? American Journal of Alzheimer's Disease and Other Dementias 2007;22:360-368.

35. Jegermalm M. Informal care and support for carers in Sweden: patterns of service receipt among informal caregivers and care recipients. European Journal of Social Work 2004;7:7-24.

36. Harrison MJ, Neufeld A. Women's experiences of barriers to support while caregiving. Health Care for Women International 1997;18:591-602. 